\title{
THE ABSENCE OF ARBITRAGE ON THE COMPLETE BLACK-SCHOLES-MERTON REGIME-SWITCHING LÉVY MARKET
}

\author{
Anna Sulima \\ Wroclaw University of Economics and Business, Wroclaw, Poland \\ Department of Econometrics and Operational Research \\ Faculty of Economics and Finance \\ e-mail: anna.sulima@ue.wroc.pl
}

ORCID: 0000-0002-6947-6192

\section{(C) 2021 Anna Sulima}

This work is licensed under the Creative Commons Attribution-ShareAlike 4.0 International License.

To view a copy of this license, visit http://creativecommons.org/licenses/by-sa/4.0/

Quote as: Sulima, A. (2021). The absence of arbitrage on the complete Black-Scholes-Merton regimeswitching Lévy market. Econometrics. Ekonometria. Advances in Applied Data Analysis, 25(3).

DOI: 10.15611/eada.2021.3.04

JEL Classification: D53, G12

\begin{abstract}
The main aim of the paper was to prove that the complete Black-Scholes-Merton regime-switching Lévy market is characterized by an absence of arbitrage. In the considered model, the prices of financial assets are described by the Lévy process in which the coefficients depend on the states of the Markov chain. Such a market is incomplete; in order to complete this market, jump financial instruments and power-jump assets were added. Then, an equivalent martingale measure was indicated and the conditions were determined so that the above model is characterized by the absence of arbitrage. Arbitrage is a trade that profits by exploiting the price differences of identical or similar financial instruments in different markets or in different forms. Thus arbitrage can be understood as risk-free profit for the trader.
\end{abstract}

Keywords: Lévy process, regime-switching, arbitrage, martingale measure.

\section{Introduction}

The main purpose of the paper was to prove that the complete Black-Scholes-Merton regime-switching Lévy market is characterised by an absence of arbitrage. On this financial market, one conducts transactions of purchase and sale of risk-free and risky securities. The dynamics of the prices of risky financial instruments were described by a stochastic differential equation called the Black-Scholes-Merton model. The original 
presented in the paper by Black and Scholes (1973) and Merton (1973) assumed that the prices of financial instruments are determined by the geometric Brownian motion. However, numerous empirical studies showed that this assumption is not adequate for the actual description of price dynamics (see Black, Jensen, and Scholes, 1972). Despite this fact, the model gained in great popularity, among others, for option pricing. The subject of this research was the Black-Scholes-Merton model, in which the price dynamics was described using the Lévy process, a generalisation of the Brownian motion (see Sato, 1999; Schoutens, 2003).

The original Black-Scholes-Merton model also assumed that the coefficients of this model are constant. Therefore, a lot of research was devoted to finding alternative models that take into account the variability of these coefficients over time. They provided more realistic ways to model the price behaviour of financial instruments, which included, among others, the jump-diffusion model presented in the paper by Merton (1976), the stochastic volatility models described by Hull and White (1987), and the regime-switching models by Naik (1993). In the regime-switching models, or Markov-modulated models, the coefficients depend on the Markov chain and change when the state of the chain alters. Therefore, regime-switching models seem to be the best for describing asset price processes. In fact, the set of parameters changes (switches) to a different state if there are structural changes in economic conditions, changes in the investment environment, etc. This analysis considered the Black-Scholes-Merton regime-switching Lévy market.

The main purpose of the paper was to find the conditions equivalent to the absence of arbitrage in the complete Black-Scholes-Merton regime-switching Lévy market. In the considered model, the prices of financial instruments are described by the Lévy process, which is a generalisation of Wiener's one. Moreover, it was assumed that the coefficients depend on the states of the Markov chain. Such a market is incomplete, which means that not every payment can be generated with an investment strategy. In order to complete this market, it is necessary to add jump assets and power-jump assets, so that each contingent claim is replicated with all the available securities.

Corcuera, Nualart, and Schoutens (2005) dealt with the lack of arbitrage on the geometric Lévy market model, but not Markov modulated. They observed whether there exists an equivalent martingale measure making all the discounted trade assets martingales.

In the paper Zhang, Siu, and Meng (2010), the authors considered a financial market where the prices of financial assets are described using the Markov-modulate Brownian motion. In a market defined in this way, an equivalent martingale measure was indicated and it was shown that discounted price processes are martingales. In this paper the author considered a more general market model, i.e. the Lévy process instead of Brownian motion.

The paper addressed the Markov additive market described by Palmowski, Stettner, and Sulima (2019), who showed that this market is free from arbitrage under 
ertain conditions. The Markov additive processes combine Levy processes with those modelled by the Markov chain, but other types of jumps also appear.

This study checked whether the market is free from arbitrage. The absence of arbitrage means that the investor cannot make a profit without taking risks. The possibility of arbitrage proves that there is a series of major errors in the valuation of instruments in the market. Such errors are very quickly noticed by arbitrators and as a result the market quickly returns to equilibrium. Thus, the market model should be one without the possibility of arbitrage (see Harrison and Pilska, 1981; Musiela and Rutkowski, 1997). The first theorem of financial mathematics is that the market is without arbitrage if and only if there is an equivalent martingale measure. Therefore, it was necessary to find an equivalent probability measure under which discounted price processes are martingales (see Jakubowski, Palczewski, Rutkowski, and Stettner, 2003), hence the author checked what conditions must be satisfied for the market to be arbitrage-free.

\section{Market model}

Let us assume that $\left(\Omega, F,\{F\}_{t}, P\right)$ is complete filtered probability space. Let the period of time $\mathrm{T}:=[0 ; T]$, where $0<T<\infty$, be established and denote the maturity time for all types of securities. Let us consider an observable Markov chain $J$ with a finite, canonical state space $E:=\left\{e_{1}, e_{2}, \ldots, e_{N}\right\}$ (Elliott, Aggoun, and Moore, 1994). Markov chains are stochastic processes, in which the probability of each event depends only on the previous one. They are a mathematical concept for describing random changes in an object. The states of the Markov chain can be identified with the states of the economy. The transition intensity matrix of the Markov chain $\boldsymbol{\Lambda}=\left[\lambda_{i j}\right]_{i, j=1,2, \ldots, N}$ is defined as follows: the elements of this matrix $\lambda_{i j}$ are constant transition intensities of the Markov chain $J$ from state $e_{i}$ to stat $e_{j}$ within the period of time $t \in \mathrm{T}$, assuming that $\lambda_{i j}>0$ for $i \neq j$.

The financial market under consideration consists of two basic instruments:

1. A bank account.

Let us assume that the interest rate $r$ is modelled by the Markov chain $J$ in the following way:

$$
r(t):=\langle r, J(t)\rangle=\sum_{i=1}^{N} r_{i}\left\langle e_{i}, J(t)\right\rangle,
$$

where $r:=\left(r_{1}, r_{2}, \ldots, r_{N}\right)^{\prime} \in \mathrm{R}_{+}^{N}$ and $\langle\cdot$,$\rangle is the scalar product in \mathrm{R}^{N}$. Coefficient $r_{i}(i=1, \ldots, N)$ is the value of the interest rate on the bank account when the Markov 
chain is in $i$-th state. Thus, the dynamics of the monetary unit value process is given by the equation:

$$
d B(t)=r(t) B(t) d t
$$

And it is assumed that $B(0)=1$. A bank account can be equated with a risk-free financial instrument.

2. A share.

Let us start with defining the Itô-Lévy process, used to describe share price dynamics. Let $\mu_{0}$ be the appreciation rate of shares and $\sigma_{0}$ be the share price volatility modelled by the Markov chain $J$ in the following way:

$$
\begin{aligned}
& \mu_{0}(t):=\left\langle\boldsymbol{\mu}_{0}, J(t)\right\rangle=\sum_{i=1}^{N} \mu_{0}^{i}\left\langle e_{i}, J(t)\right\rangle, \\
& \sigma_{0}(t):=\left\langle\boldsymbol{\sigma}_{0}, J(t)\right\rangle=\sum_{i=1}^{N} \sigma_{0}^{i}\left\langle e_{i}, J(t)\right\rangle,
\end{aligned}
$$

where $\boldsymbol{\mu}_{0}:=\left(\mu_{0}^{1}, \mu_{0}^{2}, \ldots, \mu_{0}^{N}\right)^{\prime} \in \mathrm{R}^{N}, \boldsymbol{\sigma}_{0}:=\left(\sigma_{0}^{1}, \sigma_{0}^{2}, \ldots, \sigma_{0}^{N}\right)^{\prime} \in \mathrm{R}^{N}$ and $\sigma_{0}^{i}>0$ for each $i=1,2, \ldots, N$. The coefficients of vectors $\mu_{0}^{i}$ and $\sigma_{0}^{i}$ represent the appreciation rate and volatility of the share price when the Markov chain is in the state of $e_{i}$. Let us assume that $\mu_{0}^{i}>r_{i}$ for each $i=1,2, \ldots, N$. This condition makes it possible to avoid arbitrage in the market. In addition, the following was defined:

$$
\gamma(t, x):=\langle\gamma(x), J(t)\rangle=\sum_{i=1}^{N} \gamma_{i}(x)\left\langle e_{i}, J(t)\right\rangle,
$$

where $\gamma(x):=\left(\gamma_{1}(x), \gamma_{2}(x), \ldots, \gamma_{N}(x)\right)$ is the vector of function value. The model in which the coefficients are modelled by the Markov chain is called a regime-switching model.

Process $X$ is called the Itô-Lévy process if it has the following decomposition (Oksendal and Sulem, 2004):

$$
X(t)=X(0)+\int_{0}^{t} \mu_{0}(s) d s+\int_{0}^{t} \sigma_{0}(s) d W(s)+\int_{0}^{t} \int_{\mathrm{R}} \gamma(s-, x) \bar{N}(d s, d x),
$$

where $W$ stands for the standard Brownian motion independent of $J$, whereas $\bar{N}(d t, d x)=N(d t, d x)-v(d x) d t$ is a compensated Poisson measure, independent of $J$ and $W$.

With these notations, it was assumed that the dynamics of share prices $S_{0}$ is given by the Markov-modelled Itô-Lévy process as follows: 


$$
\left\{\begin{array}{l}
d S_{0}(t)=S_{0}(t)\left(\mu_{0}(t) d t+\sigma_{0}(t) d W(t)+\int_{\mathrm{R}} \gamma(t-, x) \bar{N}(d t, d x)\right), \\
S_{0}(0)>0 .
\end{array}\right.
$$

The market described above is called the Black-Scholes-Merton regime-switching Lévy market and it is a special case of the Markov-additive market (see Palmowski et al., 2019). The difference between these two market models is that in the Black-Scholes-Merton regime-switching Lévy model, one can explicitly determine optimal investment strategies (cf. Sulima, 2019), and in the other, one cannot.

The market consisting of a bank account and shares described above, is incomplete, meaning that some payoffs cannot be replicated by trading in marketed securities. The author completed this market by adding jump assets and power-jump assets.

Completeness is an important property of the market from a theoretical and practical point of view. In the complete market, one can value any financial instrument. The principle of martingale valuation says that the value of a financial instrument $F$ at the initial moment equals $E_{Q}\left(F_{T} / B\right)$, where $B$ is a risk-free asset, and $Q$ is a martingale measure. It is an expected value relative to the martingale measure $Q$ of the discounted values of the instrument $F$ until maturity $T$. On such a market, one can not only value the instruments, but also self-protect against risk. The complete market is one market where all risk factors can be perfectly prevented and investors can buy insurance contracts to protect all derivatives and themselves against the future situation in the world.

To complete the Black-Scholes-Merton regime-switching Lévy market, the study defined jump assets and power-jump assets.

Let us define the point process $\Phi_{j}$. Let $T_{n}(n=1,2, \ldots)$ denote the jump epochs of the Markov chain $J$, where $0 \leq T_{1} \leq T_{2} \leq \ldots$. Then, the process

$$
\Phi_{j}(t):=\Phi\left([0, t] \times e_{j}\right)=\sum_{n \geq 1} 1_{\left\{J\left(T_{n}\right)=e_{j}, T_{n} \leq t\right\}}
$$

is called a marked point process (cf. Zhang, Elliott, Siu, and Guo, 2012, p. 290). Process $\Phi_{j}$ describes the number of jumps of the Markov chain to the state $e_{j}$ till time $t$. Let us define function $\phi_{j}$ as: $\phi_{j}(t):=\int_{0}^{t} \lambda_{j}(s) d s$, where

$$
\lambda_{j}(t):=\sum_{i \neq j} 1_{\left\{J(t-)=e_{i}\right\}} \lambda_{i j}
$$

and $\lambda_{i j}$ comes from matrix $\boldsymbol{\Lambda}$ defined before. 
Then, the process

$$
\bar{\Phi}_{j}(t):=\Phi_{j}(t)-\phi_{j}(t)
$$

is the martingale and is called $j$-th jump martingale (cf. Elliott, 1976; Palmowski, Stettner, and Sulima, 2018).

Next, the author defined jump price processes of financial instruments, the dynamics of which is described by jump martingales. Let us assume that these coefficients are modulated by the Markov chain in the following way:

$$
\mu_{j}(t)=\left\langle\boldsymbol{\mu}_{j}, J(t)\right\rangle=\sum_{i=1}^{N} \mu_{j}^{i}\left\langle e_{i}, J(t)\right\rangle, \sigma_{j}(t)=\left\langle\boldsymbol{\sigma}_{j}, J(t)\right\rangle=\sum_{i=1}^{N} \sigma_{j}^{i}\left\langle e_{i}, J(t)\right\rangle,
$$

where $\quad \boldsymbol{\mu}_{j}:=\left(\mu_{j}^{1}, \mu_{j}^{2}, \ldots, \mu_{j}^{N}\right)^{\prime} \in \mathrm{R}_{+}{ }^{N} \quad$ and $\quad \boldsymbol{\sigma}_{j}:=\left(\sigma_{j}^{1}, \sigma_{j}^{2}, \ldots, \sigma_{j}^{N}\right)^{\prime} \in \mathrm{R}_{+}{ }^{N}$. Coefficients $\mu_{j}^{i}$ and $\sigma_{j}^{i}$ represent the appreciation rate and volatility of the financial instrument when the economy is in $i$-th state of the Markov chain, also assuming that $\mu_{j}^{i} \geq r_{i}, \quad i=1,2, \ldots, N$. It is required to avoid arbitrage in the market.

Let $S_{j}$ be the price process of $j$-th jump asset, the dynamics of which is described as follows:

$$
\left\{\begin{array}{l}
d S_{j}(t)=S_{j}(t)\left[\mu_{j}(t) d t+\sigma_{j}(t-) d \bar{\Phi}_{j}(t)\right] \\
S_{j}(0)>0
\end{array}\right.
$$

One should note that when $J(t)=e_{j}$, then $d \bar{\Phi}_{j}(t)=0$. Therefore, $\sigma_{j}^{j}$ has no influence on the value on the right side (4). Otherwise, regardless of the value which $\sigma_{j}^{j}$ has, it does not affect the dynamics of the price process $S_{j}(t)$. As a result, without the loss of generality, one can assume that $\sigma_{j}^{j}=0$, so $\boldsymbol{\sigma}_{j}$ is a vector with $j$-th coordinate that equals 0 .

In addition, the author extend the market with securities that were first introduced by Corcuera et al. (2005), namely the so-called power-jump assets. First, let us introduce the process $X^{(k)}$ defined as:

$$
X^{(k)}(t)=\sum_{0<s \leq t}(\Delta X(s))^{k}, \quad k \geq 2,
$$

where $\Delta X(s)=X(s)-X\left(s^{-}\right)$and $X\left(s^{-}\right)=\lim _{t \rightarrow s^{-}} X(t)$. For $k=1$ let us assume $X^{(1)}(s)=X(s)$. The process $X^{(k)}$ is called the $k$-th power-jump process. One should note that $X^{(k)}$ is the Lévy-Itô process and these processes jump at the same 
time points as the original Lévy-Itô process, but the jump sizes are $k$-th powers of the jump size of the original Lévy-Itô process. For $k \geq 2$, from Protter (2005), it follows that:

$$
\mathrm{E} X^{(k)}(t)=\mathrm{E}\left(\sum_{0<s \leq t}(\Delta X(s))^{k}\right)=\int_{0}^{t} \int_{\mathrm{R}} \gamma^{k}(s, x) v(d x) d s<\infty,
$$

and therefore processes

$$
\bar{X}^{(k)}(t)=X^{(k)}(t)-\int_{0}^{t} \int_{\mathrm{R}} \gamma^{k}(s, x) \nu(d x) d s, \quad k \geq 2,
$$

are martingales, called Teugels martingales of order $k$ (see Schoutens and Teugels, 1998).

Now, the author completed the market by adding a set of $k$-th power-jump assets. The price process coefficients were determined in a similar way as for $S_{j}$, namely,

$$
\sigma^{(k)}(t):=\left\langle\boldsymbol{\sigma}^{(k)}, J(t)\right\rangle=\sum_{j=1}^{N} \sigma_{j}^{(k)}\left\langle e_{j}, J(t)\right\rangle,
$$

where $\boldsymbol{\sigma}^{(k)}:=\left(\sigma_{1}^{(k)}, \sigma_{2}^{(k)}, \ldots, \sigma_{N}^{(k)}\right)^{\prime} \in \mathrm{R}_{+}{ }^{N}$ for $k \geq 2$. The new prices processes $S^{(k)}$ were defined in the following way (for $k \geq 2$ ):

$$
\left\{\begin{array}{l}
d S^{(k)}(t)=S^{(k)}(t)\left[r(t) d t+\sigma^{(k)}(t-) d \bar{X}^{(k)}\right] \\
S^{(k)}(0)>0
\end{array}\right.
$$

The interpretation of the additional financial instruments discussed above is described by Corcuera et al. (2005). The second degree power-jump process is identified with contracts implementing variance (see Barndorff-Nielsen and Shephard, 2003, 2004). These contracts are the subject of regular transactions and they are quoted on OTC markets. The third degree power-jump process is related to the asymmetry of the underlying instrument, whereas the fourth degree - to kurtosis. What is more, assets of a power-jump of a degree greater than four are identified with insurance in the case of extreme events.

The complete Black-Scholes-Merton regime-switching Lévy market has the following form (the proof of completeness can be found in Sulima (2018)): 


$$
\left\{\begin{array}{l}
d B(t)=r(t) B(t) d t, \\
d S_{0}(t)=S_{0}(t-)\left(\mu_{0}(t) d t+\sigma_{0}(t) d W(t)+\int_{\mathrm{R}} \gamma(t-, x) \bar{N}(d t, d x)\right), \\
d S_{j}(t)=S_{j}(t-)\left[\mu_{j}(t) d t+\sigma_{j}(t-) d \bar{\Phi}_{j}(t)\right], \\
d S^{(k)}(t)=S^{(k)}(t-)\left[r(t) d t+\sigma^{(k)}(t-) d \bar{X}^{(k)}(t)\right],
\end{array}\right.
$$

for $j=1, \ldots, N, k=2,3, \ldots$.

\section{Equivalent martingale measure and absence of arbitrage}

A well-defined financial market model should meet the above assumptions, for example, the model would be unacceptable from an economic point of view if the investor were able to earn additional profit without the risk. Such a situation may take place when there is a possibility of arbitrage in the model. This study proved that arbitrage is not possible on the market under consideration.

The basic theorem about the valuation of financial assets is that the existence of an equivalent martingale measure is equivalent to the absence of arbitrage on the market:

Theorem 1. (Björk and Näslund, 1998, Prop. 6.1). If there exists a martingale measure $Q$ equivalent to $P$ then the market is arbitrage-free.

Now, let us define this type of measure.

Theorem 2. (Boel and Kohlmann, 1980, p. 515). Let $\psi_{0}$ and $\psi_{j}$ be integrable processes for all $j=1,2, \ldots, N$. Therefore

$$
\begin{gathered}
L(t)=\exp \left[\int_{0}^{t} \psi_{0}(s) d W(s)-\frac{1}{2} \int_{0}^{t} \psi_{0}^{2}(s) d s-\sum_{j=1}^{N} \int_{0}^{t} \psi_{j}(s) \phi_{j}(d s)\right] \\
\times \prod_{j=1}^{N} \prod_{X(s-) \neq X(s)}\left(1+\psi_{j}(s)\right)
\end{gathered}
$$

is a local martingale.

Let $\mathrm{Q}$ be a probability measure on $(\Omega, \mathrm{F}, \mathrm{F}, \mathrm{P})$ for $t \in \mathrm{T}$ in such that

$$
L(t)=\frac{d \mathrm{Q}}{d P} \mid \mathrm{F}_{t} .
$$

Then $L$, defined by the formula (6), is the density process of the new martingale measure $Q$. From the generalised version of the Girsanov theorem for the jumpdiffusion processes one has the following theorem: 
Theorem 3. (Boel and Kohlmann, 1980). On $\left(\Omega, F, F_{t}, Q\right)$ defined

$$
\bar{X}^{\mathrm{Q}}(t):=\int_{0}^{t} \sigma_{0}(s-) d W^{\mathrm{Q}}(s)+\int_{0}^{t} \int_{\mathrm{R}} \gamma(s-, x) \bar{N}(d s, d x),
$$

where $W^{\mathrm{Q}}(t):=W(t)-\int_{0}^{t} \psi_{0}(s) d s$ is the standard Brownian motion with respect to $\mathrm{Q}$. Moreover, for $j=1,2, \ldots, N$,

$$
\bar{\Phi}_{j}^{\mathrm{Q}}(t):=\Phi_{j}(t)-\int_{0}^{t}\left(1+\psi_{j}(s)\right) \phi_{j}(d s)
$$

are martingales with respect to $Q$.

Let us note that $\bar{X}^{(k)}(t)$ for $k \geq 2$ and $\bar{N}(d s, d x)$ do not change their form in relation to the new probability measure $Q$.

The complete Black-Scholes-Merton regime-switching Lévy market in relation to the new measure $Q$ is described by the following equations:

$$
\left\{\begin{array}{c}
d B(t)=r(t) B(t) d t \\
d S_{0}(t)=S_{0}(t-)\left(\left(\mu_{0}(t)+\sigma_{0}(t) \psi_{0}(t)\right) d t+\sigma_{0}(t-) d W^{\mathrm{Q}}(t)+\int_{\mathrm{R}} \gamma(t, x) \bar{N}(d t, d x)\right), \\
d S_{j}(t)=S_{j}(t-)\left[\left(\mu_{j}(t)+\sigma_{j}(t) \lambda_{j}(t) \psi_{j}(t)\right) d t+\sigma_{j}(t-) d \bar{\Phi}_{j}^{\mathrm{Q}}(t)\right], \\
d S^{(k)}(t)=S^{(k)}(t-)\left[r(t) d t+\sigma^{(k)}(t-) d \bar{X}^{(k)}(t)\right],
\end{array}\right.
$$

for $j=1, \ldots N$ and $k=2,3, \ldots$. To find the conditions under which the probability measure $Q$ is the martingale measure, thus it was necessary to investigate whether the discounted price processes are martingales. Using stochastic integration by parts of equations (7), discounted price processes take the following form:

$$
\left\{\begin{array}{c}
d \tilde{S}_{0}(t)=\tilde{S}_{0}(t-)\left(\left(\mu_{0}(t-)+\sigma_{0}(t-) \psi_{0}(t)-r(t-)\right) d t+\sigma_{0}(t-) d W^{Q}(t)+\int_{\mathrm{R}} \gamma(t, x) \bar{N}(d t, d x)^{\prime},\right. \\
d \tilde{S}_{j}(t)=\tilde{S}_{j}(t-)\left[\left(\mu_{j}(t-)+\sigma_{j}(t-) \lambda_{j}(t) \psi_{j}(t)-r(t-)\right) d t+\sigma_{j}(t-) d \bar{\Phi}_{j}^{Q}(t)\right], \\
d \tilde{S}^{(k)}(t)=d \tilde{S}^{(k)}(t-) \sigma^{(k)}(t-) d \bar{X}^{(k)}(t),
\end{array}\right.
$$

where $\tilde{S}_{j}(t):=B^{-1}(t) S_{j}(t)$ and $\tilde{S}^{(k)}(t):=B^{-1}(t) S^{(k)}(t)$. Let us note that $\tilde{S}^{(k)}(t)$ are martingales for $k=2,3, \ldots$. In order for $\tilde{S}_{j}$ to be martingales, the following equations must be satisfied: 


$$
\left\{\begin{array}{c}
\mu_{0}(t-)+\sigma_{0}(t-) \psi_{0}(t)-r(t-)=0, \\
\mu_{j}(t-)+\sigma_{j}(t-) \lambda_{j}(t) \psi_{j}(t)-r(t-)=0 .
\end{array}\right.
$$

Note that if $J(t)=e_{j}$ then from (3) it follows that $\lambda_{j}(t)=0$, hence in this case, if $\mu_{j}^{j} \neq r_{j}$, the martingale condition will never be satisfied. Therefore, one cannot find an equivalent martingale measure so that the discounted price processes of all financial instruments in an extended market are martingales in relation to measure $Q$. This means that there are arbitrage possibilities in an extended market. In order to eliminate them, one must assume that $\mu_{j}^{j}=r_{j}$ for all $j=0,1, \ldots, N$. Thus, processes $\psi_{j}(t)$, $j=0,1, \ldots, N$. from (8), have the following form:

$$
\begin{gathered}
\psi_{0}(t)=\frac{r(t-)-\mu_{0}(t-)}{\sigma_{0}(t-)}, \\
\psi_{j}(t)=\frac{r(t-)-\mu_{j}(t-)}{\sigma_{j}(t-) \lambda_{j}(t)}, \text { when } J(t) \neq e_{j}, \\
\psi_{j}(t)=0 \text { otherwise. }
\end{gathered}
$$

Note that processes $\psi_{j}(t),(j=0,1, \ldots, N)$ are bounded therefore the density process L (defined in (6)) is martingale and discounted price processes (7) are martingales (see Palmowski et al. (2018, Remark 2)) .

The above analysis leads to the following theorem.

Theorem 4. Let us assume that $\mu_{j}^{j}=r_{j}$ for all $j=0,1, \ldots, N$ and $\psi_{j}(t)$ $(j=0,1, \ldots, N)$ are expressed by equations $(9)$. Then the discounted price processes in the complete market (7) are martingales with respect to the new martingale measure $Q$ and the complete Black-Scholes-Merton regime-switching Lévy market is arbitrage-free.

On a finite market, the absence of arbitrage is characterized by the existence of an equivalent martingale measure, while completeness holds if and only if the equivalent martingale measure is unique. Note that the complete Black-Scholes-Merton regime-switching Lévy market has infinitely many financial instruments. On an infinite market the property of uniqueness does not hold, i.e., if the market is complete one can have more than one equivalent martingale measure. Artzner and Heath (1995) constructed a market with many countable securities for which there are two equivalent martingale measures under which the market is complete.

On the complete arbitrage-free Black-Scholes-Merton regime-switching Lévy market the study determined the optimal investment strategy (see Sulima, 2019). The optimal investment strategy is one that maximizes the expected utility of the terminal wealth. Denote by $\pi(\mathrm{t})=\left(\pi_{0}(s), \pi_{1}(s), \ldots, \pi_{N}(s), \pi^{(k)}(s), \ldots\right)$ a portfolio strategy, 
where $\pi_{0}$ is the proportion of wealth invested in stock, $\pi_{j},(j=1,2, \ldots, N)$ is the proportion of wealth invested in the $j$-th jump assets, and $\pi^{(k)}, k \geq 1$ is the proportion of wealth invested in the k-th power-jump assets. Then the optimal investment strategies for the log utility function are as follows (see Sulima, 2019):

$$
\begin{gathered}
\pi_{0}^{*}(s)=\frac{\mu_{0}(s-)-r(s)}{\sigma_{0}^{2}(s-)}, \\
\pi_{j}^{*}(s)=\frac{\mu_{j}(s-)-r(s)}{\left(r(s)-\mu_{j}(s-)\right) \sigma_{j}(s-)+\lambda_{j}(s) \sigma_{j}^{2}(s-)}, \\
\pi^{(1) *}(s)=\frac{r(s)-\mu_{0}(s-)}{\sigma_{0}^{2}(s-) \sigma^{(1)}(s-)}, \\
\pi^{*(k)}=0, \quad \text { for } \quad j=1, \ldots, N, \quad k>1,
\end{gathered}
$$

and for the power utility function:

$$
\begin{gathered}
\pi_{0}^{*}=\frac{\mu_{0}^{i}-r_{i}}{\left(\sigma_{0}^{i}\right)^{2}(1-\alpha)^{\prime}} \\
\pi_{j}^{*}=\frac{\left(1-\frac{\mu_{j}^{i}-r_{i}}{\lambda_{i j} \sigma_{j}^{i}}\right)^{\frac{1}{\alpha-1}}-1}{\sigma_{j}^{i}}, \\
\pi^{*(1)}=-\frac{\mu_{0}^{1}-r_{1}}{\left(\sigma_{0}^{1}\right)^{2}(1-\alpha) \sigma_{1}^{(1)}}, \\
\pi^{*(k)}=0 \text { for } j=1, \ldots, N, k>2 .
\end{gathered}
$$

These investment strategies are unique for each utility function.

\section{Conclusions}

The absence of arbitrage is an important property for financial markets, which means that an investor cannot make a profit without taking a risk. This research addressed determining the conditions so that the complete Black-Scholes-Merton regime-switching Lévy market model is characterised by the absence of arbitrage.

An equally important characteristic of the financial market regarding the lack of arbitrage is completeness, because in a complete market one can value all financial instruments. In a complete market without arbitrage, the arbitral price (see Jakubowski, 2006) of a financial instrument is calculated as the expected value of discounted 
payments at maturity in relation to the equivalent martingale measure. Completeness and the absence of arbitrage allow to correctly define the optimal investment strategies in this market (see Sulima, 2019).

\section{References}

Artzner, P., and Heath, D. (1995). Approximate completeness with multiple martingale measures. Mathematical Finance, 5, 1-11.

Barndor-Nielsen, O. E., and Shephard, N. (2003). Realised power variation and stochastic volatility models. Bernoulli, 9, 243-265.

Barndor-Nielsen, O. E., and Shephard, N. (2004). Financial volatility: Stochastic volatility and Lévy based models. Cambridge: Cambridge University Press.

Björk, T., and Näslund, B. (1998). Diversified portfolios in continuous time. European Financial Review, 1, 361-387.

Black, F., Jensen, M. C., and Scholes, M. (1972). The capital asset pricing model: Some empirical tests. In Jensen, M.C. (Ed.), Studies in the theory of capital markets. New York: Praeger, 79-121.

Black, F., and Scholes, M. (1973). The pricing of options and corporate liabilities. The Journal of Political Economy, 81, 637-659.

Boel, R., and Kohlmann, M. (1980). Semi-martingale models of stochastic optimal control with applications to double martingales. SIAM Journal on Control and Optimization, 18, 511-533.

Elliot, R. (1976). Double martingales. Probability Theory and Related Fields, 34, 17-28.

Elliott, R. J., Aggoun, L., and Moore, J. B. (1994). Hidden Markov models: Estimation and control. Berlin: Springer-Verlag.

Corcuera, J. M., Nualart, D., and Schoutens, W. (2005). Completion of a Lévy market by power-jump assets. Finance and Stochastics, 9(1), 109-127.

Harrison, J. M., and Pilska, S. (1981). Martingales and Stochastic Integrals in the Theory of Continuous Trading. Stochastic Processes and Their Applications, 11, 215-260.

Hull, J., and White, A. (1987). The pricing of options on assets with stochastic volatility. Journal of Finance, 42, 281-300.

Jakubowski, J. (2006). Modelowanie rynków finansowych. Warszawa: SCRIPT.

Jakubowski, J., Palczewski, A., Rutkowski, M., and Stettner, Ł. (2003). Matematyka finansowa. Instrumenty pochodne. Warszawa: WNT.

Merton, R. C. (1973). The theory of rational option pricing. Bell Journal of Economics and Management Science, 4, 141-183.

Merton, R. C. (1976). Option pricing when underlying stock returns are discontinuous. Journal of Financial Economics, 3, 125-144.

Musiela, M., and Rutkowski, M. (1997). Martingale methods in financial modelling. Berlin: Springer-Verlag.

Naik, V. (1993). Option valuation and hedging strategies with jumps in the volatility of asset returns. The Journal of Finance, 48, 1969-1984.

Oksendal, B., and Sulem, A. (2004). Applied stochastic control of jump diffusions. Springer.

Palmowski, Z., Stettner, Ł., and Sulima, A. (2018). A note on chaotic and predictable representations for Itô-Markov additive processes. Stochastic Analysis and Applications, 36(4), 622-638.

Palmowski, Z., Stettner, Ł., and Sulima, A. (2019). Optimal portfolio selection in an Itô-Markov additive market. Risks, 7(1).

Protter, P. E. (2005). Stochastic integration and differential equations: A New Approach, 2 ed., Berlin: Springer-Verlag. 
Sato, K. (1999). Lévy processes and infinitely divisible distributions. Cambridge Studies in Advanced Mathematics no. 68, Cambridge, UK.: Cambridge University Press.

Schoutens, W. (2003). Lévy Processes in Finance: Pricing Financial Derivatives. John Wiley and Sons, Ltd.

Schoutens, W., and Teugels, J. L. (1998). Lévy processes, polynomials and martingales. Communications in Statistics. Stochastic Models, 14(1 and 2), 335-349.

Sulima, A. (2018). Zupełność markowsko modelowanego rynku Blacka-Scholesa-Mertona typu Lévy'ego. Zarządzanie i Finanse, 16(4), 265-280.

Sulima, A. (2019). Optymalna strategia inwestycyjna na rynku finansowym Blacka-Scholesa-Mertona typu Lévy’ego, Studia i Prace Kolegium Zarządzania i Finansów/Szkoła Główna Handlowa, 171, 19-36.

Zhang, X., Elliott, R. J., Siu, T. K., and Guo, J. Y. (2012). Markovian regime-switching market completion using additional Markov jump assets. IMA Journal of Management Mathematics, 23(3), 283-305.

Zhang, X., Siu, T. K., and Meng, Q. (2010). Portfolio selection in the enlarged Markovian regime-switching market. SIAM Journal on Control and Optimization, 48, 3368-3388.

\section{BRAK ARBITRAŻU NA ZUPELNYM PRZELĄCZNIKOWYM RYNKU BLACKA-SCHOLESA-MERTONA TYPU LEVY'EGO}

Streszczenie: Głównym celem artykułu jest udowodnienie, że zupełny, przełącznikowy rynek Blacka-Scholesa typu Lévy’ego charakteryzuje się brakiem arbitrażu. W rozważanym modelu ceny instrumentów finansowych opisane są przez proces Lévy’ego, którego współczynniki zależą od stanów łańcucha Markowa. Taki rynek jest niezupełny, co oznacza, że nie każdą strategię inwestycyjną można replikować za pomocą dostępnych instrumentów finansowych. Aby uzupełnić ten rynek, dodano skokowe instrumenty finansowe oraz aktywa potęgowo skokowe. Następnie wskazano równoważną miarę martyngałową oraz wyznaczono warunki, tak aby powyższy model charakteryzował się brakiem arbitrażu. Arbitraż to strategia kupna lub sprzedaży, która przynosi zyski dzięki wykorzystaniu różnic cen identycznych lub podobnych instrumentów finansowych na różnych rynkach lub w różnych formach. W związku z tym arbitraż można rozumieć jako zysk wolny od ryzyka.

Slowa kluczowe: proces Lévy’ego, model przełącznikowy, arbitraż, miara martyngałowa. 